\title{
Expression of PGR, HBEGF, ITGAV, ITGB3 and SPP1 genes in eutopic endometrium of infertile women with endometriosis during the implantation window: a pilot study
}

\author{
Michele G Da Broi ${ }^{1}$, Carlos V Rocha Junior ${ }^{1}$, Juliana Meola ${ }^{1}$, Wellington P Martins ${ }^{1}$, Filomena M Carvalho ${ }^{2}$, Rui A \\ Ferriani ${ }^{1}$, Paula A Navarro, ${ }^{1,3}$ \\ ${ }^{1}$ Human Reproduction Division, Department of Obstetrics and Gynecology, Ribeirão Preto School of Medicine, \\ University of São Paulo, Ribeirão Preto, SP, Brazil. \\ 2 Department of Pathology, University of São Paulo, São Paulo, Brazil. \\ ${ }^{3}$ National Institute of Hormones and Woman's Health, CNPq, Brazil.
}

This study was presented at the $19^{\text {th }}$ Brazilian Congress of Assisted Reproduction, Buzios, RJ, Brazil, August, 2015

\begin{abstract}
Objective: Alterations in endometrial receptivity may be involved in the etiopathogenesis of endometriosis-related infertility. The literature has suggested that patients with endometriosis present progestin resistance, which could affect embryo implantation. We question the presence of alterations in the expression of the progesterone receptor gene (PGR) and the genes related to endometriumembryo interaction regulated by progesterone. This pilot study compared the expression of PGR, HBEGF, ITGAV, $I T G B 3$, and SPP1 genes in eutopic endometrium during the implantation window (IW) in infertile women with endometriosis with that observed in the endometrium of fertile and infertile controls.
\end{abstract}

Methods: In this prospective case-control study, endometrial biopsies were performed during the IW in patients aged between 18 and 45 years old, with regular cycles and without endocrine/systemic dysfunctions, divided into endometriosis (END), infertile control (IC) and fertile control (FC) groups. Total RNA extraction, CDNA synthesis, and gene expression analysis by Real-Time PCR were performed. We assessed the size of the difference that our series was powered to detect.

Results: From the 687 patients who underwent diagnostic videolaparoscopy or tubal ligation at the University Hospital, 130 were eligible. Of these, 32 had endometrial samples collected, with 17 confirmed in the IW. Fifteen samples ( 5 END, 5 IC and 5 FC) were analyzed. There was no significant difference in the expression of any studied gene. Our sample size allowed us to identify or discard large differences (two standard deviations) among the groups.

Conclusion: Endometriosis doesn't cause large changes in the endometrial expression of $P G R, H B E G F$, ITGAV, ITGB3 and SPP1 during the IW.

Keywords: endometriosis, infertility, endometrium, embryo implantation

\section{INTRODUCTION}

Endometriosis is a disease characterized by the implantation and growth of ectopic endometrial tissue (glands and/or stroma) (Gupta et al., 2006; Burney \& Giudice, 2012), being frequently associated to infertility (Practice Committee of the American Society for Reproductive Medicine, 2012). However, the exact mechanisms involved in the etiopathogenesis of infertility in patients with the disease have not yet been completely understood (Holoch \& Lessey, 2010). In this sense, evidences have suggested that impaired endometrial receptivity, resulting from molecular disorders in eutopic endometrium, may negatively impact fertility in women with the disease (Giudice \& Kao, 2004; Wei et al., 2009; Bulletti et al., 2010).

In the receptive period, called implantation window, the human endometrium undergoes molecular, histological, and structural changes that promote embryo implantation and pregnancy development (Paulson, 2011; Sharma \& Kumar, 2012; von Grothusen et al., 2014). During the implantation window, there is an increased expression of various growth factors, cytokines and adhesion molecules involved in the embryo implantation process (Aghajanova et al., 2008), so that inadequacies in the control of gene expression may result in aberrant endometrial growth and differentiation (Munro et al., 2010).

Progesterone plays an important role in regulating the implantation window, by coordinating molecular changes that culminate with endometrial receptivity establishment (Young, 2013). Acting through specific nuclear receptors that function as ligand-activated transcription factors, this steroid starts a crucial gene cascade, whose products can have both autocrine and paracrine effects, and thus, regulate the expression of other genes essential for implantation (Young, 2013). Nevertheless, there is evidence that infertile women with endometriosis are partially resistant to progesterone (Burney et al., 2007; Bulun, 2010), which may be due to an abnormal progesterone signaling as a result of aberrant expression of its receptors (Bedaiwy et al., 2015). The human progesterone receptor is encoded by the $P G R$ gene, whose function is to act as a transcriptional regulator of progesterone-responsive genes (Wu et al., 2006). Among the molecules coordinated by progesterone that are crucial to implantation process, there is the heparin-binding epidermal growth factor (HB-EGF), whose secretion in stromal cells is induced by progesterone, and whose function is to increase av $\beta 3$ integrin expression in the adjacent epithelial cells (Sharkey \& Smith, 2003). This integrin, in turn, is an adhesion molecule expressed on the apical surface of pinopodes during the implantation window that acts as a receptor of soluble ligands, such as osteopontin, and promotes signal transduction (Sharkey \& Smith, 2003). Osteopontin is a glycoprotein of the extracellular matrix secreted into the lumen, which can mediate early endometrial-trophoblast interactions during implantation (Lessey, 2002; Jessmon et al., 2009; Wei et al., 2009). Thus, as progesterone acts directly and indirectly on the endometrium, defects in progesterone receptors 
may trigger a series of alterations in the expression of molecules that are essential to the implantation process, such as those above mentioned.

In this context, the literature presents conflicting studies evaluating progesterone receptors (Attia et al., 2000; Igarashi et al., 2005; Shen et al., 2015), avß3 integrin (Ordi et al., 2003; Wei et al., 2009; Casals et al., 2012) and osteopontin (Burney et al., 2007; Cho et al., 2009; Wei et al., 2009; Casals et al., 2012) in the eutopic endometrium of women with endometriosis, especially with respect to disease-associated infertility. Moreover, to date, there is no study evaluating the expression of HB-EGF in these patients and no previous study simultaneously evaluated the expression of these five genes in infertile patients with endometriosis. Whereas the identification of molecular differences in the eutopic endometrium of women with endometriosis during implantation window is an important step to understand the pathogenesis of disease-related infertility, susceptible to support new therapeutic approaches, this study aimed to compare the expression of $P G R$ (progesterone receptor), HBEGF (heparin-binding epidermal growth factor), ITGAV and ITGB3 (av $\beta 3$ integrin) and SPP1 (osteopontin) genes in eutopic endometrium of infertile women with endometriosis, infertile controls and fertile controls, during the implantation window.

\section{MATERIALS AND METHODS}

\section{Study design}

A prospective case-control study was carried out in the University Hospital. The study was approved by the Research Ethics Committee of the University Hospital (grant 6383/2011).

\section{Settings and duration}

From December 2011 to December 2014, the patients who previously underwent diagnostic videolaparoscopy or tubal ligation at the University Hospital were evaluated according to the eligibility criteria, and those who were considered eligible were interviewed. An endometrial sample was collected from the patients who consented to participate.

\section{Participants - Eligibility Criteria}

The patients with regular cycles (every 24-38 days, 4.5 to 8 days of duration and flow up to $80 \mathrm{ml}$ per cycle) (Fraser et al. , 2007) for at least three months prior to the study, age between 18 and 45 years, body mass index (BMI) $\leq 30 \mathrm{~kg} /$ $\mathrm{m}^{2}$, no polycystic ovary syndrome and no other etiologies of chronic anovulation, hydrosalpinx and chronic diseases such as diabetes mellitus or other endocrinopathies, cardiovascular disease, dyslipidemia, systemic lupus erythematosus and other rheumatologic diseases, HIV infection, any active infection, smoking, and use of hormonal medication, anti-inflammatory drugs during the three months preceding the beginning of the study were included. The endometriosis group consisted of patients with infertility exclusively associated to endometriosis diagnosed and classified by videolaparoscopy according to the American Society for Reproductive Medicine criteria (1997). The infertile control group consisted of patients with infertility attributable to male and/or tubal factors who had ruled out endometriosis and other pelvic diseases. The fertile control group was formed by sterilized patients, proven fertile (at least one living child), without possible associated endometrial factors.

The exclusion criteria for all groups were reports of menstrual cycle alterations and use of hormonal medication during the monitoring before sample collection, and inability to attend at the scheduled date. All samples that were classified outside the implantation window after the endometrial dating were excluded.

\section{Sample collection and processing}

The patients had endometrial samples collected during the implantation window period (Wilcox et al., 1999; Sharma \& Kumar, 2012), according to the day of the menstrual cycle. For standardization, ovulation day was considered as the $14^{\text {th }}$ day of a 28 -day menstrual cycle and the implantation window was considered to be the one between the $20^{\text {th }}$ and $24^{\text {th }}$ days of the cycle. Endometrial biopsies were performed at the Human Reproduction Division, Department of Obstetrics and Gynecology, Ribeirao Preto School of Medicine (FMRP-USP), by an experienced physician using Pipelle catheter under sterile conditions.

Immediately after collection, the endometrial samples were divided into two parts: one placed in $10 \%$ formaldehyde for histological analysis, and the other placed in RNA-Later (Ambion Life technologies, Warrington, UK), maintained at $4^{\circ} \mathrm{C}$ for $24 \mathrm{~h}$ and subsequently stored at $-80 C^{\circ}$ until total RNA extraction.

\section{Endometrial dating}

All samples were classified according to the day of the menstrual cycle at the time of collection based on the menstrual history and confirmed by classical histological analysis with hematoxylin-eosin (HE) (Bedaiwy et al., 2015), carried out according to the criteria of Noyes (Noyes et al., 1975), by an experienced pathologist (F.M.C.) blinded to patients' clinical data and group-identifying information.

\section{Gene expression}

The integrity of extracted total RNA was evaluated in the Agilent Technologies 2100 Bioanalyzer $^{\mathrm{TM}}$ apparatus (Agilent) according to the manufacturer's instructions. RNA samples with RNA Integrity Number (RIN) $\geq 7.0$ were considered appropriate. The intact samples were quantified in the Qubit ${ }^{\circledR}$ fluorometer (Invitrogen).

One microgram of total RNA from each sample was reversely transcribed using the High Capacity cDNA Transcription Kit (Applied Biosystems Life Technologies) according to the manufacturer's instructions. Relative quantification of PGR, HBEGF, ITGAV, ITGB3 and SPP1 genes were analyzed using an ABI PRISM ${ }^{T M} 7500$ FAST Sequence Detection System (Applied Biosystems, Warrington, UK). The reactions were performed using the TaqMan Gene Expression Assays system (TaqMan ${ }^{\circledR}$ MGB probes, $\mathrm{FAM}^{\mathrm{TM}}$ dye-labeled), from Applied Biosystems. The $B 2 M$ and $A C T B$ genes were used as reference genes for the normalization of reactions. The primers and probes for PGR (Hs01556702_m1), HBEGF (Hs00181813_m1) ITGAV (Hs00233808_m1), ITGB3 (Hs01001469_m1), SPP1 (Hs00959010_m1), ACTB (Hs99999903_m1) and B2M (Hs00984230_m1) were obtained using the Assay-onDemand ${ }^{\mathrm{TM}}$ Gene Expression Products (Applied Biosystems, Warrington, UK).

In order to test the efficiency of inventoried TaqMan ${ }^{\circledR}$ assays, and to identify the appropriate concentration of CDNA in which the efficiencies would be between 90 and $110 \%$, we performed a real-time PCR efficiency curve test, with serial dilutions (1:2) using a cDNA pool of 3 samples from each group ( 9 samples in total). All assays had adequate efficiency and, based on this analysis, the 1:8 cDNA dilution was chosen. Quantitative Real-time PCR was performed in triplicate for each sample according to the following conditions: $5 \mu \mathrm{L}$ of $\operatorname{TaqMan}^{\circledR}$ Fast Advanced Master Mix (2x) (Applied Biosystems, Warrington, UK), 
$0.5 \mu \mathrm{L}$ of the TaqMan Gene Expression Assay, inventoried

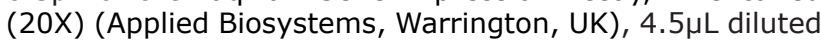
CDNA in a final volume of $10 \mu \mathrm{L}$ reaction. The reaction conditions were $50^{\circ} \mathrm{C}$ for 2 minutes, $95^{\circ} \mathrm{C}$ for 20 seconds, 40 cycles of $95^{\circ} \mathrm{C}$ for 3 seconds and $60^{\circ} \mathrm{C}$ for 30 seconds.

The relative quantification (RQ) of the analyzed genes was calculated for each sample, according to the efficiency of each assay by the $(1+E)^{-\Delta \Delta C T}$ method, where $E$ is the efficiency obtained in the efficiency curve test. The ACTB and $B 2 M$ (reference genes) and the calibrator (value obtained with the average of the CTs of the samples of the fertile control group) were used as standard-setting for the calculation.

\section{Potential sources of bias}

Selection bias was avoided by inviting all patients who underwent diagnostic videolaparoscopy or tubal ligation and fulfilled eligibility criteria to participate in the study. Between-group imbalances in covariates related to implantation and endometrial receptivity were avoided by adopting highly selective eligibility criteria for patient inclusion. The exclusion criteria were conditions potentially related to endometrial receptivity impairment or gene expression alteration. Reporting bias was avoided by presenting and analyzing all results obtained.

\section{Study size}

Considering the lack of data in the literature to estimate mean and standard deviation of $P G R, H B E G F$, ITGAV, ITGB3 and SPP1 genes simultaneously quantified, we designed a pilot study powered to detect or discard differences between the groups (Cohen, 1988). Thus, all eligible patients who agreed to participate and who donated appropriate samples were included in the study.

\section{Statistical Methods}

Statistical analysis was performed using the GraphPad Prism software (version 6.0, GraphPad Software, La Jolla, CA, USA). For comparisons between endometriosis, infertile control and fertile control groups, we applied the Kruskal-Wallis test. Significance was set as $p<0.05$. We also determined the minimum difference (in SDs) that our analyzed sample had sufficient power to detect.

\section{RESULTS}

From December 2011 to December 2014, 687 patients who underwent diagnostic videolaparoscopy $(n=629)$ or tubal ligation $(n=58)$ at the University Hospital were evaluated according to the eligibility criteria. One-hundred thirty patients were eligible, 97 of them were interviewed and 33 were not found. Twenty-three of the interviewed patients did not agree to participate in the study and 32 of the 64 who wanted to participate were excluded ( 9 for menstrual cycle alterations, 14 for use of hormonal medication, 6 for starting Assisted Reproduction Treatment and 3 patients were unable to attend the sample collection at the scheduled date). Thus, 32 patients provided written informed consent and had endometrial samples collected. Among them, 11 were infertile women with endometriosis ( 4 stage I, 2 stage II, 2 stage III and 3 stage IV), 13 were infertile controls and 8 were fertile controls. Among the 32 samples collected, 17 samples had endometrial dating confirmed by histological evaluation, being 6 infertile women with endometriosis ( 2 stage I, 1 stage II, 1 stage III and 2 stage IV), 6 infertile controls and 5 fertile controls. Two patients had total RNA inadequate to perform the Real Time PCR. Thus, 15 samples had expression quantified, among them, 5 infertile women with endometriosis (2 stage I, 1 stage II, 1 stage III and 1 stage IV), 5 infertile controls and 5 fertile controls (Figure 1 ).
The endometriosis, infertile control and control fertile groups showed no significant differences concerning age and BMI (Table 1). According to Real Time PCR results, all genes had detectable expression in all samples. However, there was no significant difference in the expression levels of any of the studied genes when comparing endometriosis, infertile control and fertile control groups (Figure 2). The median and interquartile range of the gene expression levels are presented in Table 1 . With a sample size of 5 women in each group, this study would have an $80 \%$ power to detect 2 standard-deviations difference in the expressions of PGR, HBEGF, ITGAV, ITGB3 and SPP1 genes among the groups (women with endometriosis, infertile controls and fertile controls).

\section{DISCUSSION}

Progesterone plays a fundamental role in endometrium preparation during the implantation window, coordinating several genes related to endometrial receptivity (Young, 2013), so that defects in its receptor can trigger a number of changes in the expression of molecules that are essential to the implantation process. Evidence has suggested that disorders in the eutopic endometrium are involved in impaired fertility in women with endometriosis (Giudice \& Kao, 2004; Wei et al., 2009; Bulletti et al., 2010). In order to evaluate the role of endometrial receptivity in the etiopathogenesis of disease-related infertility, this study simultaneously compared the expression of progesterone receptor $(P G R)$ coding genes and of molecules direct or indirectly regulated by progesterone, such as heparinbinding epidermal growth factor (HBEGF), av $\beta 3$ integrin (ITGAV and ITGB3) and osteopontin (SPP1) in eutopic endometrium of infertile women with endometriosis and infertile and fertile controls during the implantation window.

Although the literature reports on the occurrence of progesterone resistance (Osteen et al., 2005; Burney et al., 2007; Bulun, 2010) and changes in PR-A and PR-B receptors in women with endometriosis (Attia et al., 2000; Igarashi et al., 2005; Shen et al., 2015), the preliminary findings of this study showed no large differences in the PGR gene expression among the groups. It is important to note that the sample size adopted in the present study only allowed evaluation of large differences among the groups. However, further studies with larger series may clarify the existence of moderate or small differences in the expression of this gene, so that the present findings could help in the respective sample size calculation. Another important point to consider is that the different selection criteria adopted in other studies may have contributed to the different findings, since other authors included fertile patients with endometriosis and did not exclude many of the possible factors that could influence the gene expression and/or endometrial receptivity.

Regarding av $\beta 3$ integrin, the findings corroborate the data of the only two studies that evaluated its levels in the eutopic endometrium of infertile patients with endometriosis I/II by immunohistochemistry and did not identify differences when compared to infertile and fertile controls (Ordi et al., 2003; Casals et al., 2012). Nevertheless, in both studies, the infertile control group consisted of patients with unexplained infertility, which could represent a sampling bias, since we cannot exclude a possible endometrial factor in these cases. Added to this, the testing power of the Ordi et al. (2003) study was low, while Casals et al. (2012) did not report this data, making it impossible to draw consistent conclusions about the role of this integrin in the disease-related infertility. 


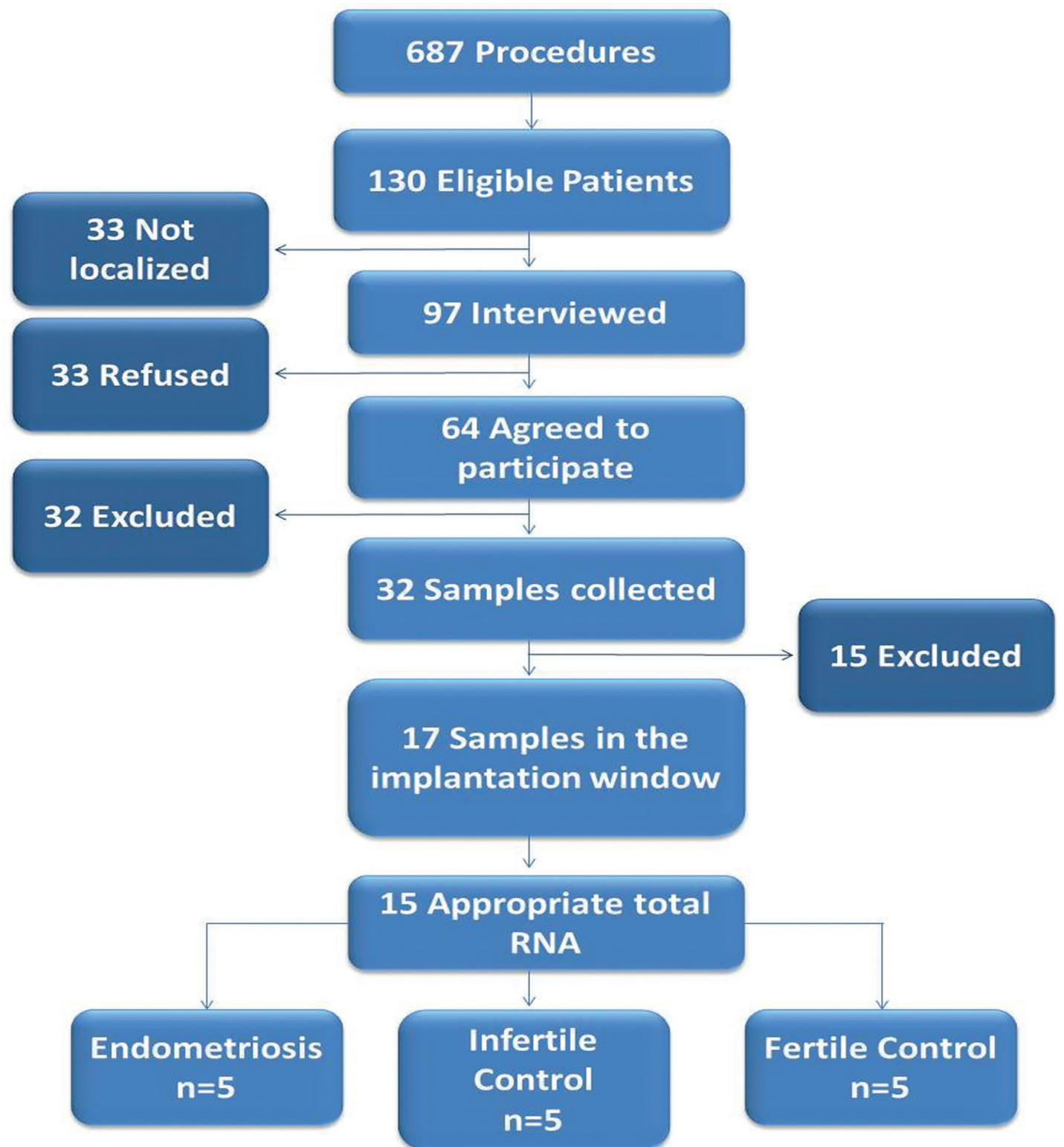

Figure 1. Study Flow Chart.

Table 1. Age, BMI and relative expression of PGR, HBEGF, ITGAV, ITGB3 and SPP1 genes by the (1+efficiency of assay) $\triangle \triangle C T$ method in eutopic endometrium of infertile patients with endometriosis, fertile controls and infertile controls during de implantation window

\begin{tabular}{|l|c|c|c|c|}
\hline Variable & $\begin{array}{c}\text { Endometriosis } \\
(\mathbf{n = 5})\end{array}$ & $\begin{array}{c}\text { Infertile Controls } \\
(\mathbf{n = 5})\end{array}$ & $\begin{array}{c}\text { Fertile Controls } \\
(\mathbf{n = 5})\end{array}$ & $\boldsymbol{p}$ \\
\hline Age & $34.80(29.80 ; 39.50)$ & $33.50(29.10 ; 38.50)$ & $32.90(27.85 ; 36.50)$ & 0.63 \\
\hline BMI & $21.90(21.55 ; 28.85)$ & $23.40(20.35 ; 27.30)$ & $27.20(24.40 ; 29.26)$ & 0.17 \\
\hline PGR & $0.97(0.73 ; 1.22)$ & $1.02(0.83 ; 1.26)$ & $0.94(0.76 ; 1.5)$ & 0.87 \\
\hline HBEGF & $0.63(0.54 ; 1.46)$ & $1.02(0.50 ; 3.34)$ & $1.14(0.76 ; 1.27)$ & 0.73 \\
\hline ITGAV & $0.85(0.81 ; 0.98)$ & $1.03(0.58 ; 1.20)$ & $0.85(0.81 ; 1.40)$ & 0.61 \\
\hline ITGB3 & $0.29(0.25 ; 0.96)$ & $0.50(0.45 ; 4.80)$ & $0.83(0.45 ; 3.10)$ & 0.33 \\
\hline SPP1 & $1.03(0.61 ; 1.73)$ & $0.55(0.46 ; 1.59)$ & $1.03(0.61 ; 1.73)$ & 0.62 \\
\hline
\end{tabular}

Note: data are presented as median (interquartile range). BMI: body mass index. PGR: progesterone receptor. $H B E G F$ : heparin-binding epidermal growth factor. ITGAV and ITGB3: av $\beta 3$ integrin. SPP1: osteopontin. 

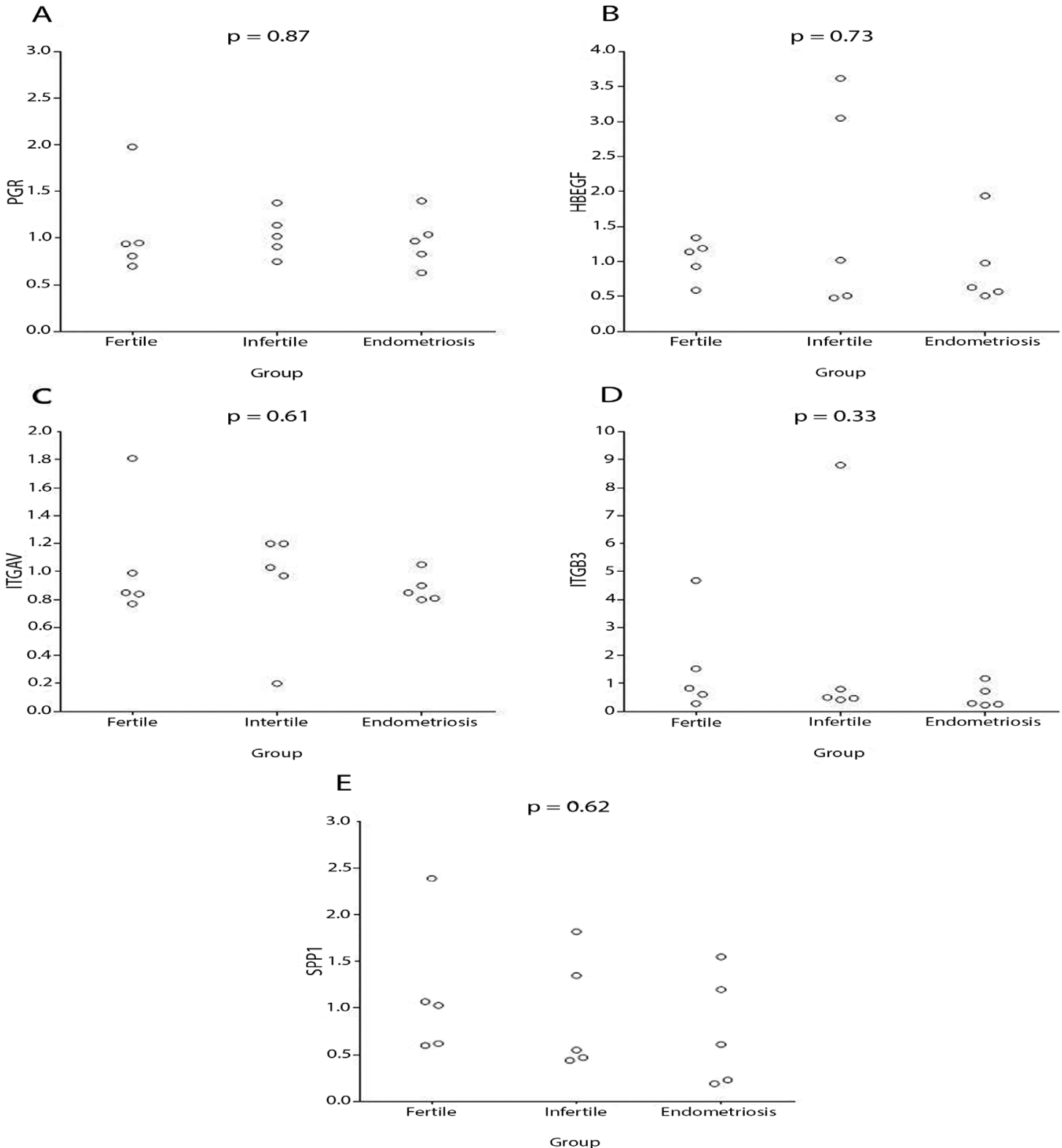

Figure 2. Relative quantification data for the PGR (A), HBEGF (B), ITGAV (C), ITGB3 (D) and SPP1 (E) genes by the $\left(1+\right.$ efficiency of assay) ${ }^{-\Delta \triangle C T}$ method in the analysis of eutopic endometrium of infertile patients with endometriosis, fertile controls and infertile controls during the implantation window.

To date, there are no studies evaluating HBEGF expression in infertile women with endometriosis, once it is the first study to rule out differences in this gene among the studied groups. On the other hand, the literature presents contradictory data regarding osteopontin expression in these patients and the present findings confirm once more the data published by Casals et al. (2012), which did not report differences in the osteopontin protein levels among the groups. In contrast, Wei et al. (2009) found reduced osteopontin expression in the eutopic endometrium of women with endometriosis during the mid and late secretory phases. Another study by the same group showed lower levels of osteopontin RNA messenger (mRNA) in women with moderate to severe endometriosis during the early secretory phase (Burney et al., 2007). On the other hand, Cho et al. (2009) showed that higher osteopontin mRNA was expressed in the eutopic endometrium and in the plasma of women with endometriosis when compared to controls. However, the authors of these studies included fertile and infertile patients with endometriosis and during different periods of the cycle, precluding the comparison of their results with those found by Casals et al. (2012) and those presented here. In the present study, the strict eligibility criteria applied avoided other factors related to impaired endometrial receptivity and our control group included only infertile patients with male and/or tubal factor infertility, excluding hydrosalpinx. However, despite no large differences found, we cannot rule out the existence of moderate or small differences.

Recently, a pilot study was published, in which eutopic endometrium of infertile women with endometriosis and infertile controls were evaluated by a microarray diagnostic tool named "Endometrial Receptivity Array" (ERA). The authors have shown no difference between groups in the expression of the evaluated 238 genes related to receptivity (Garcia-Velasco et al., 2015). However, the study did not 
present the clinical characteristics of the included patients, such as obesity, related diseases, endocrine diseases, use of medication and habits. Furthermore, within the five genes evaluated by the present study, only the SPP1 gene was included among the genes evaluated in their microarray platform. Thus, the information about the simultaneous expression of PGR, HBEGF, ITGAV and ITGB3 genes are unpublished and add new data about the molecular status of eutopic endometrium from these patients during the implantation window.

The main limitation of the study was its small sample, due to the restrictive eligibility criteria adopted, limiting its generalization. However, strict eligibility criteria, eliminating other factors possibly related to impaired endometrial receptivity and implantation are necessary in order to increase the internal validity. Also due to the small sample size it was not possible to stratify the endometriosis group into the stages of the disease

Whereas the sample size and power of the present study enable us to rule out a large difference between the groups, our preliminary findings suggest that the eutopic endometrium of infertile women with endometriosis do not present a large difference in the expression of genes related to endometrial receptivity, when compared to women with male and/or tubal factor infertility and fertile women during the implantation window. However, we cannot rule out small or moderate differences between the groups. Our findings will be useful for sample size calculation for welldesigned studies.

\section{FINANCIAL SUPPORT}

This study received financial support from the São Paulo Research Foundation (FAPESP - Fundação de Amparo à Pesquisa do Estado de São Paulo; 2011/176146) and from the National Council for Scientific and Technological Development (CNPq - Conselho Nacional de Desenvolvimento Científico e Tecnológico; 471943/20126; 140137/2015-7).

\section{ACKNOWLEDGEMENTS}

The authors thank the staff of the Human Reproduction Division, University Hospital, Department of Gynecology and Obstetrics, School of Medicine of Ribeirão Preto, University of São Paulo (FMRP-USP), specially Dr Júlio César Rosa e Silva, Dr Stael Porto Leite, Dr Anderson Melo, Dr Valeria Leitão, Dr Ludimila Seko, Dr Lilian A. Nunes, Dr Danielle M. Teixeira, Dr Clarissa V. Dias, Dr Marcela Alencar, Dr Maria Lucia Lima, Dr José Vitor Zanardi, Cristiana Padovan, Maria Auxiliadora Rosa, Ocelia Vasconcelos, Lourdes Adriana Andrade and Marisa Blanco and the staff of SERPAT Pathology Service of the Department of Pathology, FMRP-USP, specially Dr Alfredo Ribeiro and Dr Francesca Maia Faria for their valuable assistance.

\section{CONFLICTS OF INTEREST}

There are no conflicts of interest.

\section{Corresponding author:}

Michele Gomes Da Broi

Department of Obstetrics \& Gynecology

School of Medicine of Ribeirão Preto, University of São Paulo

Ribeirão Preto, SP, Brazil

E-mail address: michi.dabroi@gmail.com

\section{REFERENCES}

Aghajanova L, Hamilton AE, Giudice LC. Uterine receptivity to human embryonic implantation: histology, biomarkers, and transcriptomics. Semin Cell Dev Biol. 2008;19:20411. PMID: 18035563 DOI: $10.1016 /$ j.semcdb.2007.10.008

Attia GR, Zeitoun K, Edwards D, Johns A, Carr BR, Bulun SE. Progesterone receptor isoform $A$ but not $B$ is expressed in endometriosis. J Clin Endocrinol Metab. 2000;85:2897902. PMID: 10946900 DOI: $10.1210 /$ jcem.85.8.6739

Bedaiwy MA, Dahoud W, Skomorovska-Prokvolit Y, Yi $\mathrm{L}$, Liu JH, Falcone T, Hurd WW, Mesiano S. Abundance and Localization of Progesterone Receptor Isoforms in Endometrium in Women With and Without Endometriosis and in Peritoneal and Ovarian Endometriotic Implants. Reprod Sci. 2015;22:1153-61. PMID: 26037298 DOI: $10.1177 / 1933719115585145$

Bulletti C, Coccia ME, Battistoni S, Borini A. Endometriosis and infertility. J Assist Reprod Genet. 2010;27:441-7. PMID: 20574791 DOI: $10.1007 /$ s10815-010-9436-1

Bulun SE. Progesterone resistance and endometrial disease. Preface. Semin Reprod Med. 2010;28:3. PMID: 20104423 DOI: $10.1055 / s-0029-1242987$

Burney RO, Talbi S, Hamilton AE, Vo KC, Nyegaard $M$, Nezhat CR, Lessey BA, Giudice LC. Gene expression analysis of endometrium reveals progesterone resistance and candidate susceptibility genes in women with endometriosis. Endocrinology. 2007;148:3814-26. PMID: 17510236 DOI: $10.1210 /$ en.2006-1692

Burney RO, Giudice LC. Pathogenesis and pathophysiology of endometriosis. Fertil Steril. 2012;98:511-9. PMID: 22819144 DOI: $10.1016 / j$.fertnstert.2012.06.029

Casals G, Ordi J, Creus M, Fábregues F, Carmona F, Casamitjana R, Balasch J. Expression pattern of osteopontin and $\operatorname{av} \beta 3$ integrin during the implantation window in infertile patients with early stages of endometriosis. Hum Reprod. 2012;27:805-13. PMID: 22215628 DOI: $10.1093 /$ humrep/der432

Cho S, Ahn YS, Choi YS, Seo SK, Nam A, Kim HY, Kim $\mathrm{JH}$, Park KH, Cho DJ, Lee BS. Endometrial osteopontin mRNA expression and plasma osteopontin levels are increased in patients with endometriosis. Am J Reprod Immunol. 2009;61:286-93. PMID: 19260859 DOI: $10.1111 / \mathrm{j} .1600-0897.2009 .00692 . x$

Cohen J. Statistical Power Analysis for the Behavioral Sciences. Mahwah: Lawrence Erlbaum Associates; 1988.

Fraser IS, Critchley HO, Munro MG, Broder M; Writing Group for this Menstrual Agreement Process. A process designed to lead to international agreement on terminologies and definitions used to describe abnormalities of menstrual bleeding. Fertil Steril. 2007;87:466-76. PMID: 17362717 DOI: $10.1016 /$ j.fertnstert.2007.01.023 
Garcia-Velasco JA, Fassbender A, Ruiz-Alonso M, Blesa $D$, D'Hooghe $T$, Simon $C$. Is endometrial receptivity transcriptomics affected in women with endometriosis? A pilot study. Reprod Biomed Online. 2015;31:647-54. PMID: 26385059 DOI: 10.1016/j.rbmo.2015.07.014

Giudice LC, Kao LC. Endometriosis. Lancet. 2004;364:178999. PMID: 15541453 DOI: $10.1016 / S 0140-6736(04) 17403-5$

Gupta S, Agarwal A, Krajcir N, Alvarez JG. Role of oxidative stress in endometriosis. Reprod Biomed Online. 2006;13:126-34. PMID: 16820124 DOI: $10.1016 / S 1472-6483(10) 62026-3$

Holoch KJ, Lessey BA. Endometriosis and infertility. Clin Obstet Gynecol. 2010;53:429-38. PMID: 20436320 DOI: 10.1097/GRF.0b013e3181db7d71

Igarashi TM, Bruner-Tran $\mathrm{KL}$, Yeaman GR, Lessey $B A$, Edwards DP, Eisenberg E, Osteen KG. Reduced expression of progesterone receptor- $\mathrm{B}$ in the endometrium of women with endometriosis and in cocultures of endometrial cells exposed to 2,3,7,8-tetrachlorodibenzop-dioxin. Fertil Steril. 2005;84:67-74. PMID: 16009159 DOI: $10.1016 /$ j.fertnstert.2005.01.113

Jessmon $P$, Leach RE, Armant DR. Diverse functions of HBEGF during pregnancy. Mol Reprod Dev. 2009;76:111627. PMID: 19565643 DOI: $10.1002 / m r d .21066$

Lessey BA. Adhesion molecules and implantation. J Reprod Immunol. 2002;55:101-12. PMID: 12062825 DOI: $10.1016 / \mathrm{S} 0165-0378(01) 00139-5$

Munro SK, Farquhar CM, Mitchell MD, Ponnampalam AP. Epigenetic regulation of endometrium during the menstrual cycle. Mol Hum Reprod. 2010;16:297-310. PMID: 20139117 DOI: 10.1093/molehr/gaq010

Noyes RW, Hertig AT, Rock J. Dating the endometrial biopsy. Am J Obstet Gynecol. 1975;122:262-3. PMID: 1155504 DOI: $10.1016 /$ S0002-9378(16)33500-1

Ordi J, Creus M, Casamitjana R, Cardesa A, Vanrell JA, Balasch J. Endometrial pinopode and alphavbeta 3 integrin expression is not impaired in infertile patients with endometriosis. J Assist Reprod Genet. 2003;20:465-73. PMID: 14714826 DOI: $10.1023 /$ B:JARG.0000006709.61216.6f

Osteen KG, Bruner-Tran KL, Eisenberg E. Reduced progesterone action during endometrial maturation: a potential risk factor for the development of endometriosis. Fertil Steril. 2005;83:529-37. PMID: 15749474 DOI: 10.1016/j.fertnstert.2004.11.026
Paulson RJ. Hormonal induction of endometrial receptivity. Fertil Steril. 2011;96:530-5. PMID: 21880274 DOI: 10.1016/j.fertnstert.2011.07.1097

Practice Committee of the American Society for Reproductive Medicine. Endometriosis and infertility: a committee opinion. Fertil Steril. 2012;98:591-8. PMID: 22704630 DOI: 10.1016/j.fertnstert.2012.05.031

Revised American Society for Reproductive Medicine classification of endometriosis: 1996. Fertil Steril. 1997;67:817-21. PMID: 9130884 DOI: $10.1016 / S 0015-0282(97) 81391-X$

Sharkey AM, Smith SK. The endometrium as a cause of implantation failure. Best Pract Res Clin Obstet Gynaecol. 2003;17:289-307. PMID: 12758101 DOI: $10.1016 / S 1521-6934(02) 00130-X$

Sharma A, Kumar P. Understanding implantation window, a crucial phenomenon. J Hum Reprod Sci. 2012;5:2-6. PMID: 22870007 DOI: 10.4103/0974-1208.97777

Shen F, Yan C, Liu M, Feng Y, Chen Y. Decreased expression of mucin-1 in endometriosis endometrium correlated with progesterone receptor B involved in infertility. Arch Gynecol Obstet. 2015;291:439-45. PMID: 25155819 DOI: $10.1007 / s 00404-014-3419-x$

von Grothusen C, Lalitkumar S, Boggavarapu NR, Gemzell-Danielsson K, Lalitkumar PG. Recent advances in understanding endometrial receptivity: molecular basis and clinical applications. Am J Reprod Immunol. 2014;72:14857. PMID: 24635108 DOI: 10.1111/aji.12226

Wei Q, St Clair JB, Fu T, Stratton $P$, Nieman LK. Reduced expression of biomarkers associated with the implantation window in women with endometriosis. Fertil Steril. 2009;91:1686-91. PMID: 18672236 DOI: $10.1016 /$ j.fertnstert.2008.02.121

Wilcox AJ, Baird DD, Weinberg CR. Time of implantation of the conceptus and loss of pregnancy. $N$ Engl J Med. 1999;340:1796-9. PMID: 10362823 DOI: $10.1056 /$ NEJM199906103402304

Wu Y, Strawn E, Basir Z, Halverson G, Guo SW. Promoter hypermethylation of progesterone receptor isoform $B$ (PRB) in endometriosis. Epigenetics. 2006;1:106-11. PMID: 17965625 DOI: 10.4161/epi.1.2.2766

Young SL. Oestrogen and progesterone action on endometrium: a translational approach to understanding endometrial receptivity. Reprod Biomed Online. 2013;27:497-505. PMID: 23933037 DOI: $10.1016 /$ j.rbmo.2013.06.010 